\title{
Selectatec locking mechanism of TEC vapourisers - adding confusion to the clinical dilemma
}

\author{
KM Deepak ${ }^{1}$, RND Simha ${ }^{1}$, R Chakravarthy Murali ${ }^{2}$ \\ Consultant Anaesthetist ${ }^{1}$, Chief Consultant Anaesthetist ${ }^{2}$, Fortis Hospitals, Dept. of Anaesthesiology, \\ Critical care and Pain relief, Bannerghatta Road, Bengalaluru, Karnataka, India. 550076.
}

\section{*Corresponding author :drdeepakkm@yahoo.co.in}

\begin{abstract}
Different locking mechanism of the Selectatec vapourisers add to the confusion when being mounted on the back bar of the anaesthesia machine. Increased emphasis should be made to standardise the equipment used in anaesthesia to minimize clinical errors and improving patient safety.
\end{abstract}

Keywords : Selectatec, Back bar mounting, Vapouriser, Standardisation

We would like to bring to the notice of all the practicing anaesthesiologists and vapouriser manufacturers, the confusion created due to lack of standardisation in the selectatec locking mechanism on the back bar of anaesthesia machine while administering anaesthetics.

During routine administration of anaesthesia one of our patients had low saturation following endotracheal intubation. While troubleshooting we suspected faulty mounting of Selectatec vapouriser on to the back bar. We noticed that the locking mechanism was pointing differently as shown in figure 1 . Both the vapourisers were at different levels as shown in figure 2 .

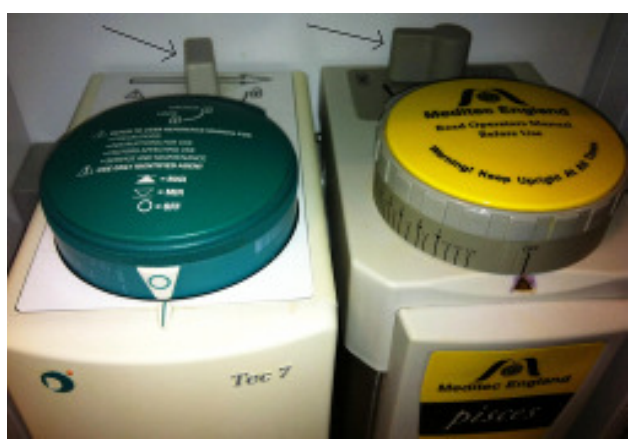

Figure 1.

Locking mechanism pointing differently (indicated by arrows)

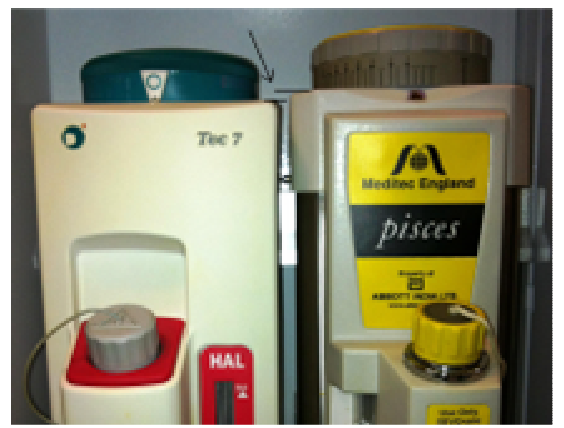

\section{Figure 2.}

The vapourisers from different companies looking similar but at different level (indicated by arrow)

Further probing revealed they were in fact mounted properly as shown in the instructions printed on them and there was no leak. Though the saturation of the patient improved on its own, valuable time was lost and led to heightened anxiety of the anaesthesiologist.

We also have different vapourisers with different Selectatec mechanisms at our hospital as shown in figures 3 and figure 4 . 


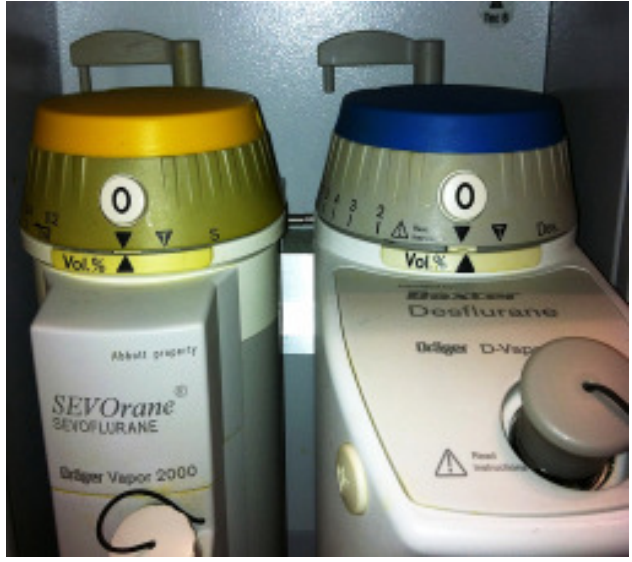

Figure 3.

Vapourisers from the same company show similar locking position

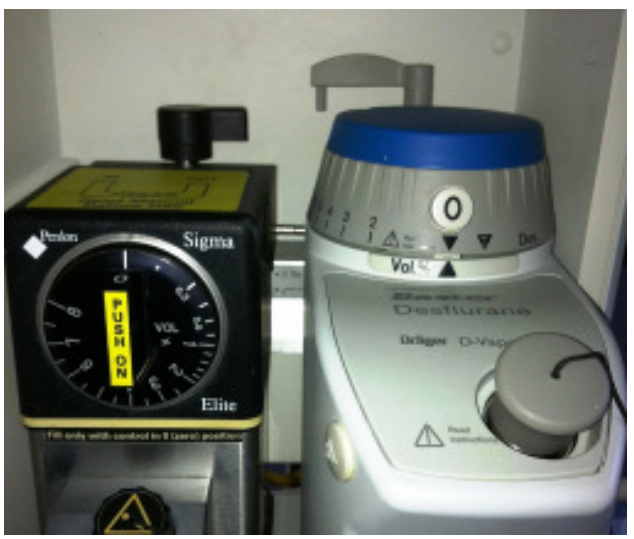

Figure 4.

Vapourisers from different companies show dissimilar locking position
It is important to keep the instruction labels on the vapouriser safely as they indicate the correct mounting on the back bar of anaesthesia machine.

Faulty mounting of vapouriser leads to leaking of anaesthetic circuits and inadequate delivery of anaesthetics leading on to awareness during surgery ${ }^{1}$.

This problem may be addressed by

1. Standardisation of the mechanism of locking of Selectatec vapouriser

2. Using vapourisers of the same make together wherever possible

3. Mandatory pre operative anaesthesia equipment check

\section{Reference}

1. Lum ME, Ngan Kee WD, Robinson BJ. Fault in a Selectatec manifold resulting in awareness. Anaesth Intensive Care. 1992 Nov;20(4):501-503. PMid:14631821.



THE COLLEGE OF ANAESTHESIOLOGISTS OF SRI LANKA

\section{GRAHAM ARTHURS PRIZE COMPETITION FOR RESEARCH WORK IN} ANAESTHESIA BY A MEDICAL STUDENT.

The rules for this prize competition are:

1. The prize is open to any medical student studying in a University in Sri Lanka on the day that the competition is held.

2. The topic can be any subject related to anaesthesia and allied interests such as critical care, pain, palliative care, nutrition or clinical assessment.

3. The work in whole or in part must not have been presented or published elsewhere.

4. Three copies of the full text should be submitted before the closing date for entries.

5. The panel of judges will select the entries that would be presented at the sessions.

6. The duration of the presentation must be no longer than 10 minutes.

7. The presentation will be judged on originality, delivery, visual aids, content, knowledge and overall impression.

8. The decision of the panel of judges in all matters relating to the competition including questions regarding eligibility shall be final.

9. The first right of publication of the entries submitted lies with the editor of the Journal of the College of Anaesthesiologists of Sri Lanka.

The closing date for the 2013 competition is $31^{\text {st }}$ October 2012. Three copies of the full text should reach the Secretary of the College before the closing date. 